\title{
An oral combined contraceptive user with elevated D-dimer post COVID-19: a case report
}

Nada A. Alyousefi ${ }^{1,2^{*}}$ (1)

\begin{abstract}
Background: This case discusses the challenges created by COVID-19 (coronavirus disease 2019) in the area of hormonal contraception, highlighting the contraception knowledge gap for women in their post COVID-19 period, especially if they had high D-dimer levels.

Case presentation: This case involves a thirty-eight-year-old woman taking combined oral contraception (desogestrel/ethinyl oestradiol tablets) with a history of varicose veins. She recovered from a COVID-19 infection in November 2020. She presented to the emergency room with right lower-limb pain below the knee and progressive swelling for five days in February 2021. Physical examination of the lower limb showed mild swelling and tenderness of the right leg compared to the left leg. D-Dimer was elevated (1.06 mcg/mL FEU). COVID-19 screening was negative. A Doppler scan to exclude DVT was performed considering the clinical picture and high D-dimer level. There was no evidence of DVT in the right limb. She was reassured and discharged with instructions on when to visit the emergency room. The D-dimer had decreased to $0.53 \mathrm{mcg} / \mathrm{mL}$ FEU in March 2021. She booked an appointment with family medicine clinics because she was concerned about the continuation of combined oral contraception (desogestrel/ethinyl oestradiol tablets) with high D-dimer and risk of thrombosis. The follow-up D-dimer level in May 2021 was normal $(0.4 \mathrm{mcg} / \mathrm{mL}$ FEU). The patient preferred to continue taking oral contraception.
\end{abstract}

Conclusion: An evidence-based consensus is needed to guide clinicians in providing contraception counselling for such patients.

Keywords: Contraception, COVID-19, Deep venous thrombosis, OCP, Venous thromboembolism, Case report

\section{Background}

Coagulopathy is common in patients with severe COVID-19, though the mechanisms are not fully understood [1-3], and the significance of persistent elevation in D-dimer in some recovered COVID-19 patients remains unknown. All combined contraceptives analysed in a Cochrane review were associated with an increased risk of venous thromboembolism [4]. However, it is unclear

\footnotetext{
*Correspondence: nalyousefi@ksu.edu.sa

1 Department of Family and Community Medicine, College of Medicine,

King Saud University, Riyadh, Saudi Arabia

Full list of author information is available at the end of the article
}

whether hormonal contraception use among COVID19-positive women increases the risk of thromboembolism [5]. This case report describes how challenging it is to provide contraception counselling for post-COVID-19 patients, especially those with elevated D-dimer.

\section{Case presentation}

The patient was a thirty-eight-year-old woman and mother of three children who delivered her youngest child in May 2019. She resumed her combined oral contraception in November 2019. She had a history of controlled bronchial asthma and hypothyroidism and used a budesonide-formoterol inhaler and levothyroxine tablets. 
She also had a history of varicose veins. In January 2020, a venous duplex scan showed a right long saphenous vein incompetent from the above knee. There was no evidence of deep vein thrombosis (DVT) or deep vein reflux. She was treated by a vascular surgeon in ambulatory care clinics in February 2020, with a plan for an elastic stocking and injection sclerotherapy. Ensuring follow-up appointments were cancelled because of the COVID-19 pandemic.

In November 2020, she presented to the emergency room due to three days of tiredness, aches and pains, and loss of taste and smell. Her swab test for COVID19 was positive. Home isolation with paracetamol and albuterol inhaler puffs for mild shortness of breath were given. No hospitalization was required. The shortness of breath symptoms resolved within days, and her senses of taste and smell recovered after 1 month.

In February 2021, she presented to the emergency room with a history of right lower-limb pain below the knee and progressive swelling for five days. The pain had increased in severity for one day; she took paracetamol, but the pain did not improve. There was no history of fever, shortness of breath or chest pain, no recent trauma or surgery, stroke, DVT, cancer, skin change, prolonged immobility, or pregnancy; she had not travelled recently. She had been taking regular oral combined contraception (OCP), i.e., desogestrel/ ethinyl oestradiol tablets, since resuming in November 2019. There was no history of contact with a confirmed case of COVID-19.

Physical examination showed a temperature of $36.5^{\circ} \mathrm{C}$ (oral), respiratory rate of 19 , blood pressure of $121 / 79$, $\mathrm{SpO} 2$ of $99 \%$, weight of $59 \mathrm{~kg}$ and BMI of 23.63. The patient was conscious, alert, and oriented. Cardiovascular exam was normal, as were chest and abdomen examinations. The lower limb of the right leg showed mild swelling and tenderness in comparison to the left leg. Her neurovascular examination was normal. Limb measurements were as follows: right calf muscle $36 \mathrm{~cm}$; right thigh muscle 49; left calf muscle 35; and left thigh muscle 48 . There was a normal range of motion; she had mild swelling in the right lower limb with no erythema.

COVID-19 screening, which was performed per the emergency room admission protocol, was negative. According to laboratory findings, WBC, RBC, Hgb, Hct, $\mathrm{MCV}, \mathrm{MCH}, \mathrm{MCHC}, \mathrm{RDW}$, platelet, MPV, renal profile, liver, and thyroid function tests were all within normal limits. However, D-dimer was high at $1.06 \mathrm{mcg} / \mathrm{mL}$ FEU (the normal range is $0.22-0.45$ ).

A Doppler scan to exclude DVT was performed considering the clinical picture and high D-dimer level. There was no evidence of DVT in the right limb vein. She was reassured and discharged with instructions to visit the emergency room. A follow-up appointment with vascular surgery was scheduled in 1 week.

When presenting to vascular surgery follow-up appointments, the lower limb pain had disappeared; she was advised to continue wearing the elastic stocking. Repeated venous duplex scan showed the same result as the initial assessment. The D-dimer level was reduced to $0.53 \mathrm{mcg} / \mathrm{mL}$ FEU (the normal range is $0.22-0.45$ ) in March 2021.

She booked an appointment with family medicine clinics because she was concerned about the continuation of combined oral contraception, i.e., desogestrel/ethinyl oestradiol tablets, with the high D-dimer level and risk of thrombosis. The follow-up D-dimer level in May 2021 was normal $(0.4 \mathrm{mcg} / \mathrm{mL}$ FEU). Although she was counselled about other types of contraception, especially with respect to her varicose veins, she decided to continue the same contraceptive.

\section{Discussion and conclusions}

The literature shows that D-dimer is commonly elevated in patients with COVID-19 [1-3]. Indeed, D-dimer levels correlate with disease severity and are a reliable prognostic marker for in-hospital mortality in patients admitted for COVID-19 [6, 7]. In patients with COVID-19 who do not require admission, no routine tests for coagulation markers, such as D-dimer level, are required in guidelines [8]. However, $30.1 \%$ of patients discharged from three large hospitals in London had persistently elevated d-dimer [9], and the value decreases over time postCOVID [9].

The literature reported a three- to fivefold increased risk of venous thromboembolism (VTE) in users of combined oral contraceptives compared to non-users [10]. Ethinyl oestradiol can increase levels of some coagulation factors and fibrinogen [11, 12]. Additionally, it can decrease plasma levels of anticoagulant factors, including antithrombin and tissue factor pathway inhibitors [11, 12].

The harm depends on the type of progestogen used and the dose of ethinyl oestradiol $[4,5,12]$. Although systematic reviews have suggested that oral progestin-only (POC) contraceptive methods do not increase the risk of venous thromboembolism, injectable POC use might increase it $[13,14]$.

Another knowledge gap is highlighted as a systematic review concerning OCP users with superficial venous disease found a limited number of studies and quality, i.e. no definitive conclusion can be made about increased VTE risk [15].

According to a panel of Spanish experts from various scientific societies, during reduced mobility of home isolation for mild COVID-19 women, it is 
recommended to withdraw combined hormonal contraception [16]. If contraception is required, they recommend that combined hormonal contraception can be continued or replaced by progestin-only contraception if there is another risk factor [16]. Interestingly, some patients with mild symptoms of COVID-19 may develop venous thromboembolic events, which indicate a hypercoagulable state $[17,18]$.

Another group of experts considers it appropriate to discontinue any combined hormonal contraceptives in patients with suspected or confirmed COVID-19 [19]. As the risk of venous thromboembolism is lower with OCP containing second-generation progestins than OCP containing third-generation progestins, they recommend using OCP containing second-generation progestins such as norgestrel or levonorgestrel [19-21]. A Cochrane review is carried out to determine whether the use of hormonal contraception increases the risk of venous and arterial thromboembolism in women with COVID-19 [5].

COVID-19 and OCP can both cause thromboembolic manifestations. Studies should evaluate the risk of venous thromboembolism among post-COVID-19 women who are on combined oral contraceptives. The current OCP guidelines for the general population should be applied for post-COVID-19 users until further scientific evidence is available.

\section{Abbreviations \\ COVID-19: Coronavirus disease 2019; DVT: Deep vein thrombosis; OCP: Oral combined contraception; VTE: Venous thromboembolism; POC: Progestin- only contraception.}

\section{Acknowledgements}

The author is grateful to the patient who was allowed to report her clinical manifestations in this report for her valuable contribution.

\section{Authors' contributions}

NA conceptualized and drafted the initial and final manuscript.

\section{Funding}

Not funded.

\section{Availability of data and materials}

Data sharing is not applicable to this article as no datasets were generated or analyzed during the current study.

\section{Declarations}

\section{Ethics approval and consent to participate}

Reporting this case was done according to the Declaration of Helsinki's ethical principles.

\section{Consent for publication}

Written informed consent was obtained from the patient for publication of this case report.

\section{Competing interests}

The author declared that she has no competing interests.

\section{Author details}

${ }^{1}$ Department of Family and Community Medicine, College of Medicine, King Saud University, Riyadh, Saudi Arabia. ${ }^{2}$ King Saud University Medical City, King Saud University, Riyadh, Saudi Arabia.

Received: 18 June 2021 Accepted: 19 August 2021

Published online: 28 August 2021

\section{References}

1. Levi M, Thachil J, Iba T, Levy JH. Coagulation abnormalities and thrombosis in patients with COVID-19. Lancet Haematol. 2020;7(6):e438.

2. Iba T, Levy JH, Levi M, Thachil J. Coagulopathy in COVID-19. J Thromb Haemost. 2020;18(9):2103-9.

3. Mucha SR, Dugar S, McCrae K, Joseph DE, Bartholomew J, Sacha G, et al. Coagulopathy in COVID-19. Cleve Clin J Med. 2020;87(8):461-8.

4. de Bastos M, Stegeman BH, Rosendaal FR, Van Hylckama VA, Helmerhorst FM, Stijnen T, et al. Combined oral contraceptives: venous thrombosis. Cochrane Database Syst Rev. 2014. https://doi.org/10.1002/14651858. CD010813.pub2.

5. Cohen MA, Stewart F, Paynter R, Edelman A, Henderson J. Risk of thromboembolism in patients with COVID-19 who are using hormonal contraception. Cochrane Database Syst Rev. 2021. https://doi.org/10. 1002/14651858.CD014908.

6. Huang Z, Yao Y, Cao J, Wang Q, Liu K, Luo Z, et al. D-dimer as a biomarker for disease severity and mortality in COVID-19 patients: a case control study. J Intensive Care. 2020;8(1):1-11.

7. Lippi G, Favaloro EJ. D-dimer is associated with severity of coronavirus disease 2019: a pooled analysis. Thromb Haemost. 2020;120(5):876.

8. World Health Organization. Clinical management of COVID-19: interim guidance, 27 May 2020. World Health Organization; 2020.

9. Mandal S, Barnett J, Brill SE, Brown JS, Denneny EK, Hare SS, et al. LongCOVID: a cross-sectional study of persisting symptoms, biomarker and imaging abnormalities following hospitalisation for COVID-19. Thorax. 2021;76(4):396-8

10. van Hylckama VA, Helmerhorst FM, Vandenbroucke JP, Doggen CJM, Rosendaal FR. The venous thrombotic risk of oral contraceptives, effects of oestrogen dose and progestogen type: results of the MEGA casecontrol study. BMJ. 2009;339:b2921.

11. Sandset PM. Mechanisms of hormonal therapy related thrombosis. Thromb Res. 2013;131:S4-7.

12. Skeith L, Le Gal G, Rodger MA. Oral contraceptives and hormone replacement therapy: how strong a risk factor for venous thromboembolism? Thromb Res. 2021;202:134-8.

13. Glisic M, Shahzad S, Tsoli S, Chadni M, Asllanaj E, Rojas LZ, et al. Association between progestin-only contraceptive use and cardiometabolic outcomes: a systematic review and meta-analysis. Eur J Prev Cardiol. 2018;25(10):1042-52. https://doi.org/10.1177/2047487318774847.

14. Tepper NK, Whiteman MK, Marchbanks PA, James AH, Curtis KM. Progestin-only contraception and thromboembolism: a systematic review. Contraception. 2016;94(6):678-700.

15. Tepper NK, Marchbanks PA, Curtis KM. Superficial venous disease and combined hormonal contraceptives: a systematic review. Contraception. 2016;94(3):275-9.

16. Ramírez I, De la Viuda E, Baquedano L, Coronado P, Llaneza P, Mendoza $\mathrm{N}$, et al. Managing thromboembolic risk with menopausal hormone therapy and hormonal contraception in the COVID-19 pandemic: Recommendations from the Spanish Menopause Society, Sociedad Española de Ginecología y Obstetricia and Sociedad Española de Trombosis y Hemos. Maturitas. 2020;137:57-62.

17. Vechi HT, Maia LR, Alves MDM. Late acute pulmonary embolism after mild Coronavirus Disease 2019 (COVID-19): a case series. Rev Inst Med Trop Sao Paulo. 2020. https://doi.org/10.1590/S1678-9946202062063.

18. Nauka PC, Oran E, Chekuri S. Deep venous thrombosis in a non-critically ill patient with novel COVID-19 infection. Thromb Res. 2020;192:27-8.

19. Kow CS, Mustafa ZU, Hasan SS. The use of combined hormonal contraceptives amid the COVID-19 pandemic. Eur J Contracept Reprod Heal Care. 2021;26(1):85-6. https://doi.org/10.1080/13625187.2020.1849618. 
20. Dragoman MV, Tepper NK, Fu R, Curtis KM, Chou R, Gaffield ME. A systematic review and meta-analysis of venous thrombosis risk among users of combined oral contraception. Int J Gynecol Obstet. 2018;141(3):287-94.

21. Hennessy S, Berlin JA, Kinman JL, Margolis DJ, Marcus SM, Strom BL.

Risk of venous thromboembolism from oral contraceptives containing gestodene and desogestrel versus levonorgestrel: a meta-analysis and formal sensitivity analysis. Contraception. 2001;64(2):125-33.

\section{Publisher's Note}

Springer Nature remains neutral with regard to jurisdictional claims in published maps and institutional affiliations.
Ready to submit your research? Choose BMC and benefit from:

- fast, convenient online submission

- thorough peer review by experienced researchers in your field

- rapid publication on acceptance

- support for research data, including large and complex data types

- gold Open Access which fosters wider collaboration and increased citations

- maximum visibility for your research: over 100M website views per year

At BMC, research is always in progress.

Learn more biomedcentral.com/submissions 